\title{
A Systematic Literature Mining of Sponge City: What Has Been Done and The Challenges Standing Ahead
}

\author{
Zongmin Li, Shuyan Xu, Liming Yao * \\ Business School, Sichuan University, Chengdu 610064, P. R. China \\ *Correspondence: yaoliming@163.com; Tel.: +86-85418191 \\ January 17, 2018
}

\begin{abstract}
As the increase threat of flood risk and environmental safety due to the urbanization, Sponge city research has been attracting extensive attention both in practical and theoretical research field. To date, there are only scattered studies about Sponge city. Moreover, vary names of Sponge city prevalent in different countries, which leads to disconnection of literature in the same field of Sponge city. In this paper, a thorough systematic literature mining of Sponge city is presented. A literature analysis system is created, which includes literature export from Web of Sciences and systematic analysis via NoteExpress and CiteSpace. Some literature statistical results are derived. Challenges and opportunities for future research are anticipated. Our goals are to promote this promising thought, summarize past research, and identify issues for future research to create impacts on the practice of Sponge city.
\end{abstract}

Keywords: Sponge city; Active, Beautiful, Clean water design; sustainable drainage systems; water-sensitive urban drainage systems; low impact developments; best management practices; literature mining; literature review

\section{Introduction}

\section{Introduction}

In last decades, urbanization process accelerates rapidly. It has resulted in more and more ecological environment turning into man-made geomorphic, which is full of metal, concrete, asphalt, glass and bricks, fundamentally changing the thermodynamics, dynamics and water cycle characteristics of the underlying surface of the city. Meanwhile, many high-rising buildings obstructed passage of air through the city, leading to vortex and accumulating the polluted air. Pollutants accumulate steam, which accounts for condensation nodule, increasing the intensity and frequency of precipitation. Such situation is especially true in China. Most cities in China, using combination way of surface drainage and pipe drainage, are lacking of surface penetration because of the hard concrete. Thus, not only the urban surface runoff raises, but the decrease of the underground water also causes the shortage of domestic water for northern cities. What's more, the unfettered expansion of urbanization has increasingly exacerbated issues that affect urban waterlogging, water resources, and the aquatic environment [1]. In 2015, Chinese government put forward the construction of 
Sponge city program, which aimed to solve the conflict between the shortage of water source and urban precipitation, and to reduce urban waterlogging.

The term "Sponge city" describes cities that are able to adapt flexibly, like sponges, to change in the environment, such that they absorb, store, permeate and purify rainwater, and are able to make use of the stored water when needed [1]. As the increase threat of environmental safety due to the urbanization, as well as the flood risk, Sponge city research has been attracting extensive attention both in practical and theoretical research field. Although large amount of literature in this field is generating, different names for the concept of Sponge city prevalent in different countries, and the research directions are scattered. To the best of authors' knowledge, there has not yet been any systematic review article about Sponge city. The newly published survey paper from Li et al. [2] is based on of all 30 pilot Sponge cities construction project in China, and is more on the regional practice side. It is still necessary to gather holistic literature in the field of Sponge city, so that to summarize the current research progress and predict future research direction through a systematic literature mining.

This section will then review the history, the vary names of Sponge city, and clarify the motivations of literature mining in this field.

\section{$2.1 \quad$ History of Sponge city}

The concept of "Sponge city" originates from the traditional urban water service model, which evolved multiple phases $[3,4,5,6]$.

At first, without complete water service structure, few sewers were only available in some large cities. With the fast pace of population growth and pollution, water pipes were invented aiming at provide a water treatment system to improve life quality of urban dwellers. During that period, Water Treatment Works (WTWs) was put forward. As paved urban areas extended, Sewage Treatment Works was proposed and combined with water pipes, sewers and WTWs to focus on flood protection and drainage. All above contributed to Sustainable Urban Water Management $(S U W M)$ [7].

Meanwhile, in the late 1970s of Switzerland, there came the first notable study that aimed at developing an urban system which is a combination of several components of water treatment, that is, Integrated Urban Drainage System (IUDS) [8]. It focuses on the integration of sewer, sewage water treatment plant, water receiving systems, and sustainable stormwater management, with economic factors taken into consideration [9].

Thereafter, Water Sensitivity Urban Design (WSUD), planned and designed by Australian scholars in 1994, came into being. It is another important western technology which contributes to Sponge City. WSUD primarily targets at minimise the adverse effects of urban development on surrounding hydrological environment [10].

Following the steps of Australia, North America formed another similar technique, named Low Impact Development (LID) in the end of 1990s, which originated as a design philosophy and has become popular in many parts of the world. The key point of LID implicates that specialists who develop and design systems are requested to minimise the impact on environment by the approaches of design and developing, and management process. During the practise of realizing LID, urban 


$$
[\text { scale }=0.55] \text { shuyanfigs } / \text { history }
$$

Figure 1: Concept and history of Sponge city

designers and developers must show their respect to water, surface soil, terrain, and vegetation, that is, to respect nature in a word, which marks the core value of LID [11].

Afte that, the Active Beautiful Clean (ABC) Waters Program was introduced in April 2006 by Singapore's water agency, Public Utilities Board. This Program is primarily used to managing urban stormwater and controlling flood referring to LID. Nowadays it is popular in both European countries and America [12]. Thus, ABC Waters Program, contributing to widespread LID technique, carry out stormwater management in a more sustainable way [12].

Although similar water treatment system met with a quick response in most western countries, it was introduced in UK rather slowly Sustainable Urban Drainage System (SUDS) [13,14]. According to the Flood and Water Management Act 2010, which was enacted by Britain, SUDS was forced to be taken into consideration in every project [15]. It focuses on making use of and strengthening natural process to simulate hydrologic development in early time, which subverts principals of rapid transit [16]. SUDS is capable to improve urban flood and water contamination; also beautify the city, and provide a more livable environment for both human and wildlife [17, 18].

Specifically in China, Sponge City is a relative new concept. It was firstly introduced in "2012 Low Carbon City and Regional Sponge Technology Development Forum" in Shenzhen, April 2012 [19]. In the following two years, Jinping $\mathrm{Xi}$, the president of China, stressed the idea of the construction of the Sponge City. With the financial support of the instructions from the central economic working conference published by the central government, Sponge urban construction pilot work was carried on $[20,21]$. In April 2, 2015, the first batch of pilot construction of Sponge City was announced, including 16 cities as follows, Qian'an, Baicheng, Zhenjiang, Jiaxing, Chizhou, Xiamen, Pingxiang, Jinan, Hebi, Wuhan, Changde, Nanning, Chongqing, Suining, Gui' an and Xi Xian new district. In regard of this, the central government aiming at subsidizing for the construction of Sponge Cities with the annual total flood control rate not less than $70 \%$ in 2020, and the pilot area not less than 75\%; the relevant control design rainfall of $23.2 \mathrm{~mm}$, and total control runoff of 9.51 million cubic meters. Until April 27, 2016, 30 cities in total were on the way of sponge process, with 14 cities more nominated as the second batch of pilot Sponge City, including Beijing, Tianjin, Dalian, Shanghai, Ningbo, Fuzhou, Qingdao, Zhuhai, Shenzhen, Sanya, Yuxi, Qingyang, Xining and Guyuan [21]. These pilot notifications promote the the sponge progress of urban construction effectively.

The concept and history of Sponge city are summarized in Figure 1.

\subsection{Motivations of mining Sponge city literature}

Given the above context, there are three main motivations of literature mining of Sponge City studies.

First, although a large body of literature has touched on the theme of Sponge City, there has not yet been any systematic review article. The main reason may be due to the difficulty of collecting 
a relatively complete bibliography. In fact, it is quite important to make a review of urban water management both longitudinally and transversely for the purpose of shedding some light on this field and provide advice for further study.

Second, given the situation of China, water problems, such as water storage, flooding, and water quality issues are so serious [22]. Finding ways to solve low utilization ratio of rainfall resource, uncontrollable flood, and sharp shortage of urban water resource admits of no delay [23]. Sponge city provides a very promising solution approach. To guide our future path, it is beneficial for us to look into what has been done and the challenges standing ahead in such field.

Third, the high speed of urbanization and industrialization put both local and regional lifesupport ecosystem into disadvantages. Only basing on ecological principals to regulate and management could guarantee sustainability. Given this knowledge, a practical tool for eco-sustainable planning and management is in urgent need [24]. The idea of Sponge city plays a pivotal part in the construction of ecological landscape. It provides a livable and sustainable environment, also become the basis of evaluating the ecological environment of urban residents. It serves for residents, while responds directly to living quality with profound meaning. It is the milestone of sustainable development of city ecological system [25]. To clarify the concept of Sponge city and promote its research, a systematic review is beneficial attempt.

\section{Method}

Literature mining is a powerful method for elucidating major trends across time in published scientific literature and allows for topic maps to be built [26]. Our primary goal of literature mining is to discover the research trend on this subject. In the rest of this section, this paper will set up a search strategy and selection criteria, and then summarize the literature from a macro perspective.

\subsection{Search strategy and selection criteria}

Literature mining was conducted in October, 2017 using the academic resource retrieval website, Web of Science (WOS). WOS is the largest comprehensive academic information resource which covers the most domains on global scale. It consists of seven databases containing information on nature science, engineering technology, biomedical and so on [27]. Owning to the broad scope of Sponge city, it is extremely difficult to gather all studies of it. Fortunately, WOS did provide us with sufficient references. In such a case, this paper is written using WOS database.

To ensure no important articles are overlooked or duplicated, the searching methodology need be in accordance with procedures below.

- Step1: To ensure an accurate and efficient process, seven key words were used in searching by "theme", including "Sponge city", "Sustainable Urban Water Management (SUWM)", "Integrated Urban Drainage System (IUDS)", "Water Sensitivity Urban Design (WSUD)", "Low Impact Development (LID)", "Active Beautiful Clean (ABC) Waters Program", and "Sustainable Urban Drainage System(SUDS)". This procedure guarantees that all vary names of Sponge city are all considered and the literature identified are all relevant. 


$$
[\text { scale }=1.05] \text { shuyanfigs } / \text { knowledge }
$$

Figure 2: The framework of the literature analysis system

- Step2: There are some repetitive publications. Using the document management software "NoteExpress", it was very easy for us to eliminate repetitive articles. Thereafter, the repetitions will be removed and a clear database will form.

- Step3: Research themes are more concentrated by combing and merging the similar keywords, e.g. Sponge City is similar to Sponge City Construction and Sponge Urban.

A final document storage of Sponge city containing 962 articles is formed, ranging from 1950 to 2018 .

\subsection{Literature analysis system}

It should be noted that citations link literatures in a specific field formally and explicitly, which is stressed by Garfield-"father of academic literature citation indexing" [28]. The conception of indexing refers to assign the content identifiers to the documents, which has been developing rapidly. This is an auto-run process, establishing intelligent and cost-efficient retrieving system. Based on an exact document set which could be read by machine, computers are capable of make analysis of the content, forming proper content identifiers and attaching them to every stored document. In such a case, users' demand could be identified and transported into machine-readable languages by Boolean combinations of index terms. Finally, match the documents and users' searching demand so as to select appropriate items [29]. Furthermore, it is easy to position a research using citation retrieving method on condition that it has significant influence on a specific field or cross-field disciplines [30].

Considering of the above, this paper established a data analysis system as shown in Figure 2. It is composed of WOS database, two softwares, namely NoteExpress and CiteSpace, through a series of functions of softwares and steps, characteristics and statistical results of Sponge city literature are obtained.

As stated in Section 2.1, WOS is the largest comprehensive academic database on global scale. It includes over 8700 core academic journals, which are most influential in each field, such as nature science, engineering technology and biomedical. Besides, it provides quite professional and abundant database retrieval functions, including common retrieval, cited literature retrieval, chemical structure retrieval, also online full text access service [31]. Moreover WOS has a nice compatibility to NoteExpress and CiteSpace. Therefore, this paper choose WOS naturally.

NoteExpress is one of the most professional literature retrieving and management tools. The core function of NoteExpress contains knowledge acquisition, management, application, and digging, covering all segments of knowledge management. The bibliography downloaded from websites could be preserved through NoteExpress, thereby managed and cited easily. It can also be used to generate concise analysis of the researching trend and structure on a particular field. It should be noted that many scholars have been achieved great success on researching using NoteExpress 
Table 1: The overall findings from final document storage Theme

Article Type

- 204 Conferen

Researchers

- Scholar distri

- Authors who published more than 10 papers include: Rauch, W (16);

Brown, RR (16); Mannina, Giorgio (15); Freni, Gabriele (12); Viviani, Gaspare (11);

Scholz, Miklas (10).

Year of study

- $310(32.22 \%)$ documents from 2001 to 2010 ; 588 (61.12\%) documents from 2011 to 2018. Journals

Landscape and Urban Planning (48), Water (32), Journal of Hydrologic Engineering (21)

Urban Water Journal (20), Environmental Modelling \& Software (18), Journal of

Hydrology (16), Water Resources Management (15), Water Research (15), etc.

$$
[\text { scale }=0.35] \text { shuyanfigs } / \text { country.jpg }
$$

Figure 3: Research distribution in different countries

$[32,33,34,30]$.

CiteSpace, one of the most popular tools for knowledge mapping, is designed as a Java application for visualizing and analyzing process through producing co-citation networks [35, 36, 37]. CiteSpace visualizes the literature in the form of a co-citation network, which draws on article citations to reveal the structure of a field or fields [36]. Besides, it can also be used to show a particular research structure in a knowledge domain [38]. To our best knowledge, CiteSpace has never been employed for Sponge city literature mining. Thus, this paper will be the first attempt to analyze the research structure of Sponge city by CiteSpace.

\section{Findings and discussion}

\subsection{Growth trend}

After further careful review and classification of our final document storage, we calculated statistical results by NoteExpress.

As shown in Table 1, there is a growing body of literature both of proceedings papers and journal articles on Sponge city. Although there were only $0.42 \%$ of documents published from 1960 to 1990 and $6.24 \%$ of documents published from 1991 to 2000, more than $93 \%$ documents published from 2001 to 2018. Therefore literature has grown rapidly in last two decades. It can be estimated that the research amount will keep growing in the following years. The distribution of scholars is scattered. The outlets of Sponge city research include a large range of academic journals from water science, water resource management, urban planning to comprehensive topic. Among these, the most important outlets are Water Science and Technology, Landscape and Urban Planning, Water, Journal of Hydrologic Engineering, Urban Water Journal, Environmental Modelling \& Software, Journal of Hydrology, Water Resources Management, Water Research.

Next, the data were imported into CiteSpace, and the analysis type "country" was selected. 


$$
[\text { width }=] \text { shuyanfigs/journaloverlay }(1)
$$

Figure 4: A dual-map overlay of the final document storage

$$
[\text { scale }=0.6] \text { shuyanfigs } / \text { cluster }
$$

Figure 5: Cited reference in different clusters

This operation aims to detect the countries that generate the most research. After running and visualizing the project, the results has been plotted out as Figure 3. We use larger size of the circles and labels to stress out the countries with more studies. As shown in Figure 3, USA generates the most Sponge city papers, accounting for $22.87 \%$ of total documents. Although the first Sponge city papers from China is as late as 2005, China publishes the second most papers, accounting for $15.7 \%$ of total studies. Followed by England and Australia, taking the percentage of $10.64 \%$ and $9.06 \%$ respectively. The top 4 countries generate almost $60 \%$ of Sponge city research, dominating the field.

Figure 4 shows a dual-map overlay of the final document storage. The dual-map overlay is designed by Chen and Leydesdorff to reveal patterns of a scientific portfolio with respect to a global map of scientific literature [39]. The so called "dual-map" refers to the citing and cited relationship in the overall visualization. Given 962 Sponge city papers, CiteSpace visualizes the disciplinary concentrations of these papers and how these papers connect various regions according to their citation relationship. Colored curves represent paths of references, originating from the citing map on the left and pointing to the cited map on the right. The nature of each area is determined by a set of journals that belong to the area, that is, a cluster. Each area is labeled by the most-common words in the titles of the corresponding journals. As shown in Figure 4, Sponge city papers primarily appears in three broad areas on the citing map: the area in the top left corner in dark blue with the label of ecology/earth/marine; the area next to it in yellow with the label of veterinary/animal/science; and the area near the bottom in light blue with the label of economics/economic/political. Citation curves that originated from each of the three major regions point to regions in the cited maps on the right, among which the most primary links in yellow or dark blue are labeled with citing and cited journals. Citation paths in dark blue, for instance, indicate that publications in ecology-, earth-, and marine- related journals cite different groups of journals, including earth/geology/geophisics and plant/ecology/zoology primarily [40, 41].

Figure 5 shows the overview of a document co-citation network generated from the core dataset. The largest cluster is in the center near the bottom of the figure, that is, \#0 case study. Each node depicts a cited reference. The citation history is visualized in terms of 'tree rings'. Nodes with citation bursts are visualized by rings in red. The largest cluster \#0 case study contains 47 members. The silhouette value of it, which measures the homogeneity of the cluster, is 0.802 , close to 1 , meaning the high reliability of this result. Case study has been identified with assistance in the problem of urban water management. It is available for scholars to do research basing on practical case and propose certain recommendations. Governments and communities are also capable of studying previous cases of practices, summarising their experiences, then selecting and utilising a 


$$
[\text { scale }=0.5] \text { shuyanfigs } / \text { citationburst }(1)
$$

Figure 6: Top 16 references with strong citation bursts

Table 2: Strongest citations began in the same year.

$\begin{array}{lccc}\text { Article } & \text { Strength } & \text { Begin } & \text { End } \\ \text { Hauger et al [42] } & 4.8234 & 2005 & 2010 \\ \text { Harremoes [43] } & 3.8863 & 2006 & 2010 \\ \text { Wong [44] } & 4.0026 & 2009 & 2011 \\ \text { Scholz et al [45] } & 5.2611 & 2010 & 2013 \\ \text { Elliott et al [46] } & 6.5237 & 2012 & 2015 \\ \text { Dietz et al [47] } & 7.8864 & 2013 & 2015 \\ \text { Ahiablame et al [48] } & 5.127 & 2015 & 2018 \\ \text { Qin et al [49] } & 7.587 & 2016 & 2018\end{array}$

set of appropriate plans.

Other large clusters in the results focus on the different designs and tools in Sponge city practices. The third largest cluster \#2, integrated urban drainage system (IUDS), which has been referred in the introduction, is an conception of integration of sewer, sewage water treatment plant, water receiving systems, and sustainable stormwater management, with economic factors taken into consideration [9]. It has been identified that with new contributors for development such as urbanization, climate change and computational efficiency, IUDS is expanding in new directions. Moreover, modeling of water systems through technical and biophysical tools is attracting increasing attentions recently.

Figure 6 shows the citation bursts of the dataset, which describes that the dynamics of a field can be characterized by articles that have received the steepest increase of citations. It shows the top 16 references with the strongest citation bursts. A citation burst represents the possibility that the community has paid or is paying special attention towards the potential contribution. Here select the strongest burst of groups began in the same year, including 7 numbers, which has been listed in Table 2. The first strongest citation burst began in year 2005 is written by Hauger et al.[42] and published in 2002. It presented and discussed a probabilistic approach to evaluating the performance of urban wastewater systems. It has 99 citations in WOS at the time of writing, coupled with the longest duration of citation among these 16 articles, that is, 6 years of duration from 2005 to 2010. The second strongest citation burst is also associated with a 2002 paper written by Harremoes [43], which mainly summarised the status of urban storm drainage as an integrated professional discipline. The citation of it began in 2006 and ended in 2010, with 63 citations in total. The third member in the table is a 2006 paper with 93 citations. It presents an overview of current state of practising WSUD in Australia and estimation of future tendency [44]. The fourth article with a stronger citation number than those above, has been cited 228 times. It is written by Scholz et al. It made a review about the wide-range literature on permeable pavement systems, summarised the research trend and put forward some recommendations for future study [45]. Next paper, written by Elliott et al. in 2007, has been cited 286 times during 2012 and 2015. It focused on the low impact urban stormwater drainage technology and made a review of the LID models 
Table 3: Research types

\begin{tabular}{l|l}
\hline \multicolumn{1}{|c|}{ Theme } & \\
\hline Type of & \\
Research & • I. Effectiveness \\
content & \\
reduction, risk/security evaluation $288(29.938 \%) ;$ & \\
- II. Modelling, planning or optimization of rainwater management system $210(21.830 \%) ;$ & \\
- III. Case study of Sponge city in various practical background 164 (17.048\%); \\
- IV. Development of new technologies/tools/approaches, such as green roof, rain garden, \\
urban hydrology 109 (11.331\%); \\
- V. Review of Sponge city practices, effectiveness, technologies, and challenges in the \\
background of climate change and urbanization $69(7.173 \%) ;$ \\
- VI. Water quality/waste/pollution control or management $45(4.678 \%) ;$ \\
- VII. Sustainability evaluation/analysis 38 (3.950\%); \\
- IX. Policy analysis and recommendations $10(1.040 \%)$.
\end{tabular}

[46]. The sixth article, published in 2007, also belongs to review of LID practices, made a summary of temporary research, such as bioretention cells, porous pavement and grassed swales [47]. It has been cited 424 times in total, which represents the strongest citation burst among all the articles in the dataset. Next one with 44 citations, also made contributions on LID technology and assessed the performance of rain barrel/cistern and porous pavement [48]. The last one in the list has a citation numbers of 57, which is a little higher than the former. Likewise, Qin et al. also focused on LID and its effects on urban flooding under different rainfall characteristics [49]. It can be figured out through examining the strongest citation burst that advanced technologies of LID practices has been paid the most close attention, as well as urban stormwater drainage, permeable pavement and urban flooding.

\subsection{Classification of research types}

Scrutinizing the paper list in the NoteExpress, we classify 962 papers in the final document storage into 9 types research content as shown in Table 3. The type I refers to effectiveness evaluation of Sponge city measures, such as comprehensive benefit evaluation system for LID of urban stormwater management measures [50], effectiveness of ABC waters design features for runoff quantity control [51], cost-effectiveness analysis on LID measures of a highly urbanized area [52]. The type I research also includes evaluation/prediction of flood runoff reduction and risk/security evaluation, such as the management of urban surface water flood risks [53], urban flood vulnerability and risk mapping [54], risk analysis of sustainable urban drainage and irrigation [55]. There are 288 papers in the type I, make contributions of $29.938 \%$ of total research. The type II refers to modelling, planning or optimization of rainwater management system, for example, Wang et al. modeled future scenarios of urban stormwater management response to impacts of climate change and urbanization [56]; Di Matteo et al. optimized the distributed stormwater harvesting systems [57]; Hellmers et al. proposed a model for decentralised systems for urban drainage and flood mitigation [58]. There are 210 papers in the type II, accounting for $21.83 \%$ of total research. The type III is case study 


$$
[\text { scale }=0.6] \text { shuyanfigs } / \text { timezone }(2)
$$

Figure 7: Appearance time of keywords

of Sponge city in various practical background, with 164 papers. It's worth noting that, most case studies are from practice of China, the number of papers is 66 , accounting for $40.24 \%$, far more than case studies from other background. For example, Sponge city practices in Beijing [59, 60, 61], Tianjin [62] etc. The type IV describes the development of new technologies, tools or approaches in this field, such as green roof [63, 64], rain garden [65, 66], urban hydrology [67], which includes 109 papers and represents $11.331 \%$. As for the type V, review of Sponge city, only takes up $7.173 \%$ of the total research, that is, 69 papers in all during the period of 1980 to 2018. This statistical result also stresses the significance of this paper, which also belongs to review, covering the history of development of Sponge City, research trends and challenges in the future. The previous reviews also contribute in different aspects, such as different practices [68, 69], effectiveness [70], technologies [71], challenges in the background of climate change and urbanization [72]. The type VI focuses on water quality, waste, and pollution control or management. Morihama et al., for example, studied on urban runoff control in Brazilian metropolitan regions and put forward integrated solutions [73]. Freni et al., researched the uncertainty of water quality modeling through the approach of variance decomposition [74]. Besides, Daigger also made contributions on wastewater management [75]. This type contains 45 numbers, occupying 4.678\%. The type VII is primarily clustered as sustainability evaluation and analysis with 38 papers accounting for $3.95 \%$ in sum, such as the sustainable development of urban stormwater practice [76], or sustainability of urban water system [77]. The type VIII refers to intelligent management or intelligent metering for urban water, for example, Fernández et al. developed a geographic information system(GIS) water management system by using some free and open source software [78]. Likewise, Fuchs L et al. also discussed the approach of using GIS to make flooding analysis in urban drainage [79]. There are just 29 numbers in this group, which takes up $3.015 \%$ of total. Finally, type IX is about policy analysis and recommendations. Only 10 papers are in this type, including sustainable water management policy [80], policy recommendations in Chinese urban flooding [81], and California zero trash policy coupled with its impacts on urban drainage [82].

It should be noted that almost $70 \%$ papers belong to the first 3 types, namely evaluation/prediction papers, planning/optimization papers and case study research, which also illustrates the major trend of this field.

Figure 7 depicts the appearance time of keywords, which is available of depicting the general trend of research in Sponge City. The same as Figure 5, each node represents a keyword. The repeating times of the keyword in the dataset are visualized in terms of 'tree rings'. Nodes with citation bursts are visualized by rings in red. Besides, the purple rings around the node (see, urban drainage, system, runoff, and city) depict the betweenness centrality, which measures the importance of the node. The links between each node refer to the first citation. This statistical result is close to the appearance time of different descriptions of Sponge city, which has been shown in introduction. Modeling is the first conception involved in this field, which appeared in year 1994. 


$$
[\text { scale }=0.6] \text { shuyanfigs } / \text { keywordsburst }
$$

Figure 8: Top 13 keywords with the strongest citation bursts.

Sponge city is put forward in 2015.

\subsection{Research foci identification}

Similar to the citation bursts, burst detection is also available of depicting bursts keywords to indicating the emerging trend. As shown in Figure 8, top 13 strongest keywords bursts present during the period between 1980 to 2018. The strongest burst among ones began in the same year include sustainable development (started in 1997), drainage system (started in 2000), real time control (started in 2002), landscape (started in 2004), water (started in 2010), removal (started in 2011), decision making (started in 2012), green-roof (started in 2013), and Sponge city (started in 2015). These results are close to the trend figured from Figure 7.

\section{Challenges and opportunities standing ahead}

As shown in the literature statistical results, there is a significant repository of literature that touches on the theme of Sponge city. It can be anticipated that Sponge city research is going to soar up in the future. As can be seen from Figure 9, there is a general increasing trend in all 9 content types. In the twenty-first century, more and more population lives in the cities. As for Asia, More than half of population now lives in cities. Cities are relatively vulnerable to surface water flooding due to the increase in artificial surfaces and decrease in green space, preventing excessive rainfall from entering the ground [83]. Climate change makes the situation even worse by causing greater extreme weather, with more severe droughts; more intermittent, but more intense storms; and higher coastal storm surges [84]. No doubt, we are facing an age of the increasing frequency and intensity of environmental disasters. Urban flooding, water pollution and water scarcity will remain priorities for a long time, and shall receives renewed attention by individuals, communities and governments. Strong support from governments will be enhanced. China's national Sponge City Programme starting from 2015 can be seen as a typical example. More and more scholars, scientific communities will devote themselves to the Sponge city studies. Looking ahead, there still exist rooms for further study and some challenges that we are facing.

(1) Seen from many case studies of Sponge city, urban water management system built based on the concept of Sponge city works effectively because of its sustainable connotation and various advanced technology. However, it is very challenging that Sponge city needs to gather and monitor data in real time which allows mining these data for details that aid in day-to-day operations, regulatory compliance, and cost savings. Big amounts of data are generated and exchanged between departments, devices and regions. Some of the data exchanged are highly uncertain. Cloud environments shall be built to store and maintain data. It is also challenging for all the sectors and systems being provided coordinated and user-friendly access to cloud platform and various databases. 


$$
\text { [width }=] \text { shuyanfigs } / \text { trends }
$$

Figure 9: Growth trends of papers in different content types

(2) Information technology has become a requisite part of municipal water management systems. Various types of sensors, e.g., smart water meters, usually work in real-time mode delivering a huge amount of data. Big data technologies must be incorporated in Sponge city practices [85]. For instance, Athanasiou et al. introduced an open water monitoring system with the name DAIAD. DAIAD addresses two significant problems in water management: the lack of (a) detailed water consumption data and (b) the necessary big data management and analysis services that can provide a better understanding of the parameters influencing water demand and sustainable consumer behavior [86]. Another inspiring concept is from Thompson and Kadiyala, who proposed an Machine-to-Machine (M2M) smart system. Improved sensor technologies and firmware applications (e.g., those that measure pressure, water quality, and flow), big data analytics tools (leveraged from other sectors), and embedded Machine-to-Machine (M2M) communications are creating new opportunities to collect data that have typically been manually collected and rarely evaluated [87].

There is a great potential for these new technologies, approaches and tools be applied to Sponge city future research. It can be noticed that the growth trend in content VIII "intelligent management or intelligent metering for urban water" is remarkable as shown in Figure 9. It is also a proof of information technology and intelligent management are becoming focus of frontier Sponge city research.

(3) As shown in Figure 9, content I, II, III, IV are mainstream research direction of Sponge cite. Such tendency will go on in the near future. We particularly looked into the content III, namely case study of Sponge city. There are most case studies carried out in cities of Asia, North America, Australia and Europe. It could be a huge opportunity to carry out case studies in other parts of the world. However, the successful experience in some places cannot be applied to other places. Measures need to be adjusted according to the every actual circumstance, which will be quite challenging.

(4) According to the citation bursts analysis, references and keywords that represent advanced technologies, approaches, sustainable development strategies and decision making methodologies received the most and longest citations. Such topics will remain hot in the future. Constant improvement of new technologies/approaches/tools and innovative urban water management methods to achieve long-term sustainable development will be the most challenging tasks for future research of Sponge city.

\section{Conclusions}

This paper conducted a thorough systematic literature mining of Sponge city. Concept and history of Sponge city are reviewed briefly. A literature analysis system is created, which includes literature export from Web of Sciences and systematic analysis via NoteExpress and CiteSpace. By applying the literature analysis system, we found that 
- Literature of Sponge city has grown rapidly in last two decades. Article types, researchers, the most important outlets and country distribution are summarized.

- Disciplinary concentrations, co-citation network, citation history of Sponge city research are visualized.

- The strongest citation bursts of references and keywords are analyzed, which shows that the advanced technologies, approaches, sustainable development strategies and decision making methodologies received the most and longest citations.

According to these literature statistical results, we predicted the challenges and opportunities of future research. We are optimistic about the development prospect of Sponge city. Establishment of cloud environments and user-friendly cloud platform/databases, application of big data analytics tools, open water monitoring system and smart system, case studies to other parts of the world, and development of technologies and management methods for longer-term sustainable development are anticipated as future challenges and opportunities.

\section{Acknowledgments}

We are thankful for financial support from the National Natural Science Foundations (Grant No. 71601134 and 71771157), Soft Science Program of Sichuan Province (Grant No. 2017ZR0154) and China Postdoctoral Science Foundation (Grant No. 2017M612983 and 2017M610609).

\section{Author Contributions}

Zongmin Li established the framework of the literature analysis system, analyzed the literature by NoteExpress, and wrote parts of Section 3, 4 and 5. Shuyan Xu downloaded the bibliographical reference on WOS, analyzed the literature by CiteSpace, and wrote Section 1, 2 and parts of Section 3. Liming Yao critiqued the draft and the literature analysis system.

\section{Conflict of Interets}

The authors declare no conflict of interest.

\section{References}

[1] Shao, W.W.; Zhang, H.X.; Liu, J.Y.; Yang, G.Y.; Chen, X.D.; Yang, Z.Y.; Huang, H. Data integration and its application in the Sponge City construction of China. Procedia Eng. 2016, $154,779-786$.

[2] Li, H; Ding, L.Q.; Ren, M.L.; Li, C.Z.; Wang, H. Sponge City construction in China: A survey of the challenges and opportunities. Water 2017, 9, 594.

[3] Tarr, J.A. Water and wastes: A retrospective assessment of wastewater technology in the United States, 1800-1932. Technol. Cult. 1984, 25, 226-263. 
[4] Geels, F.W. Processes and patterns in transitions and system innovations: Refining the coevolutionary multi-level perspective. Technol. For. Soc. Change 2005, 72, 681-696.

[5] Matthew, G. Rethinking urban metabolism: Water, space and the modern city. City 2004, 8, 363-379.

[6] Brown, R.R.; Keath, N.; Wong, T.H.F. Urban water management in cities: Historical, current and future regimes. Water Sci. Technol: J. Int. Assoc. Water. Pollut. Res 2009, 59, 847-855.

[7] David, R.M.; Magnus, M.; Stephen, C.; David J.B. Towards sustainable urban water management: A critical reassessment. Water Res. 2013, 47, 7150-7161.

[8] Gujer, W.; Krejci, V.; Schwarzenbach, R.; Zobrist, J. Von der Kanalisation ins Grundwasser Charakterisierung eines Regenereignisses im Glattal. GWF, Wasser/Abwasser 1982, 62, 298311.

[9] Hauger, M.B.; Rauche, W.; Linde, J.J.; Mikkelsen, P.S. Cost benefit risk - A concept for management of integrated urban wastewater systems. Water Sci. Technol. 2002, 45, 185-193.

[10] Morison, P.J.; Brown, R.R. Understanding the nature of publics and local policy commitment to Water Sensitive Urban Design. Landscape Urban Plann. 2011, 99, 83-92.

[11] Zhang, J. Assessing the application of Sponge City to downtown guelph. 2017.

[12] Lim, H.S.; Lu, X.X. Sustainable urban stormwater management in the tropics: An evaluation of Singapore's ABC Waters Program. J. Hydrol 2016, 538, 842-862.

[13] Asteb $\phi$ l, S.O.; HvitvedJacobsen, T.; Simonsen, $\phi$, O. Sustainable stormwater management at Fornebu - from an airport to an industrial and residential area of the city of Oslo, Norway. Sci. Total Environ. 2004, 334-335, 239-249.

[14] Nordeidet, B.; Nordeide, T.; Åsteb $\phi$ l, S.O.; Hvitved, J.T. Prioritising and planning of urban stormwater treatment in the Alna watercourse in Oslo. Sci. Total Environ. 2004, 334-335, $231-238$.

[15] Flood and Water Management Act; London Councils, Liz Bartlett, U.K.2011.

[16] Jones, P.; Neil, Macdonald. Making space for unruly water: Sustainable drainage systems and the disciplining of surface runoff. Geoforum 2007, 38, 534-544.

[17] Charlesworth, S.M. A review of the adaption and mitigation of global climate using sustainable drainage cities. J. Water Clim. Change 2010, 1, 165.

[18] Norton, B.A.; Coutts, A.M.; Livesley, S.J.; Harris, R.J.; Hunter, A.M.; Williams, N.S.G. Planning for cooler cities: A framework to prioritise green infrastructure to mitigate high temperatures in urban landscapes. Landscape Urban Plann. 2015, 134, 127-138. 
[19] Xing, M.L.; Han, Y.M.; Jiang, M.M.; Li, H.X. The review of Sponge City. Presented at the International Conference on Sustainable Energy and Environment Engineering, Zhuhai, China, November 2016.

[20] Wu, D.J.; Zhan, S.Z.; Li, Y.H. Research on the emerging trend and practice of Chinese characteristic sponge cities. Chin. Soft Sci. 2016, 1, 79-97.

[21] K.J. Yu, D.H. Li, H. Yuan. Water supply and drainage in western. 2015, 6, 26-36.

[22] Zhang, J. Assessing the application of Sponge City to downtown Guelph. 2017.

[23] Embassy of the Kingdom of the Netherlands, I and M department. Factsheet Sponge City Construction in China. 2016.

[24] Wang, R.S.; Li, F.; Hu, D.; Li, B.L. Understanding eco-complexity: Social-economic-natural complex ecosystem approach. Ecol. Complexity 2011, 8, 15-29.

[25] Chao, M.L. Urban ecological landscape "Sponge Bob City" concept under remodeling research. Thesis, Henan Univisity, 2015.

[26] Bruijn, B.D.; Martin, J. Getting to the (c)ore of knowledge: mining biomedical literature. Int. J. Med. Inf. 2002, 67, 7-18.

[27] Xu, J.P.; Li, Z.M. A review on ecological engineering based engineering management. Omega 2012, 40, 368-378.

[28] Morman, E.T. Indexing: Its theory and application in science, technology, and humanities by eugene garfield. Isis 1985, 21, 714 .

[29] Nicolaisen, J. Bibliometrics and citation analysis: From the science citation index to cybermetrics. J. Am. Soc. Inf. Sci. Technol. 2010, 61, 205-207.

[30] Zheng, B.B.; Xu, J.P.; Ni, T.; Li, M.H. Geothermal energy utilization trends from a technological paradigm perspective. Renewable Energy 2015, 77, 430-441.

[31] Ridley, C.E.; Clark, C.M.; LeDuc, S.D.; Bierwagen, B.G.; Lin, B.B.; Mehl, A.; Tobias, D.A. Biofuels: network analysis of the literature reveals key environmental and economic unknowns. Environ. Sci. Technol. 2012, 46, 1309-15.

[32] Xu, J.P.; Li, Z.M. A review on ecological engineering based engineering management. Omega 2012, 40, 368-378.

[33] Li, C.; Xiong, K.N.; Wu, G.M. Process of biodiversity research of Karst areas in China. Acta Ecol. Sin. 2013, 33, 192-200.

[34] Liu, B.; Guo, S.D. Attentions on grey system theories by China scholars-based on literature metrology during 1982-2009. J. Grey Syst. 2010, 22, 137-146. 
[35] Chen, C. Searching for intellectual turning points: Progressive knowledge domain visualization. Proc. Natl. Acad. Sci. U. S. A. 2004, 101, 5303-5310.

[36] Chen, C.M. CiteSpace II: Detecting and visualizing emerging trends and transient patterns in scientific literature. J. Am. Soc. Inf. Sci. Technol. 2006, 57, 359-377.

[37] Chen, P.; Hu, H. How determinant attributes of service quality influence customer perceived value: An empirical investigation of the Australian coffee outlet industry. Int. J. Contemp. Hosp. Manage. 2010, 22, 535-551.

[38] Li, X.J.; Ma, E.; Qu, H.L. Knowledge mapping of hospitality research: A visual analysis using CiteSpace. Int. J. Contemp. Hosp. Manage. 2017, 60, 77-93.

[39] Chen, C.M.; Leydesdorff, L. Patterns of connections and movements in dual-map overlays: A new method of publication portfolio analysis. J. Assoc. Info. Sci. Technol. 2014, 65, 334-351.

[40] Chen, C.M. CiteSpace II: Detecting and visualizing emerging trends and transient patterns in scientific literature. J. Assoc. Info. Sci. Technol. 2009, 57, 359-377.

[41] Chen, C.M.; Dubin, R.; Kim, M.C. Emerging trends and new developments in regenerative medicine: a scientometric update (2000-2014). Expert Opin. Biol. Ther. 2014, 14, 1295-317.

[42] Hauger, M.B.; Rauch, W.; Linde, J.J.; Mikkelsen, P.S. Cost benefit risk- A concept for management of integrated urban wastewater systems? Water Sci. Technol. J. Int. Assoc. Water Pollut. Res. 2002, 45, 185-93.

[43] Harremoës, P. Integrated urban drainage, status and perspectives. Water Sci. Technol. J. Int. Assoc. Water Pollut. Res. 2002, 45, 1.

[44] Wong, T.H.F. Water sensitive urban design- The journey thus far. Aust. J. Water Resour. 2006, 10, 213-222.

[45] Scholz, M.; Grabowiecki, P. Review of permeable pavement systems. Build. Sci. 2007, 42, $3830-3836$.

[46] Elliott, A.H.; Trowsdale, S.A.A. Review of models for low impact urban stormwater drainage. Environ. Model. Software 2007, 22, 394-405.

[47] Dietz, M.E. Low Impact Development practices: A review of current research and recommendations for future directions. Water, Air, Soil Pollut. 2007, 186, 351-363.

[48] Ahiablame, L.M.; Engel, B.A.; Chaubey, I. Effectiveness of low impact development practices in two urbanized watersheds: Retrofitting with rain barrel/cistern and porous pavement. $J$. Environ. Manage. 2013, 119, 151-161.

[49] Qin, H.P.; Li, Z.X.; Fu, G.T. The effects of low impact development on urban flooding under different rainfall characteristics. J. Environ. Manage. 2013, 129, 577-85. 
[50] Li, J.; Deng, C.; Li, Y.; Song, J. Comprehensive benefit evaluation system for Low-Impact Development of urban stormwater management measures. Water Resour. Manage. 2017, 31, $4745-4758$.

[51] Yau, W.K.; Radhakrishnan, M.; Liong, S.Y.; Zevenbergen, C.; Pathirana, A. Effectiveness of ABC Waters design features for runoff quantity control in urban Singapore. Water 2017, 9, 577.

[52] Liao, Z.L.; Chen, H.; Huang, F.; Li, H.Z. Cost-effectiveness analysis on LID measures of a highly urbanized area. Desalin. Water Treat. 2015, 56, 2817-2823.

[53] Viavattene, C.; Ellis, J.B. The management of urban surface water flood risks: SUDS performance in flood reduction from extreme events. Water Sci. Technol. 2013, 67, 99-108.

[54] Ouma, Y.O.; Tateishi, R. Urban flood vulnerability and risk mapping using integrated multiparametric AHP and GIS: Methodological overview and case study assessment. Water 2014, $6,1515-1545$.

[55] Ursino, N. Risk analysis of sustainable urban drainage and irrigation. Adv. Water Resour. 2015, 83, 277-284.

[56] Wang, M.; Zhang, D.Q.; Su, J.; Tan, S.K. Future scenarios modeling of urban stormwater management response to impacts of climate change and urbanization. CSAWAC 2017, 45.

[57] Matteo, M.D.; Dandy, G.C.; Maier, H.R. Multiobjective optimization of distributed stormwater harvesting systems. J. Water Resour. Plann. Manage. 2017, 143.

[58] Hellmers, S.; Manojlovic, N.; Palmaricciotti, G.; Froehle, P. Modelling decentralised systems for urban drainage and flood mitigation. J. Appl. Water Eng. Res. 2017, 5, 61-69.

[59] Jia, H.; Yu, S.L.; Qin, H. Low impact development and Sponge City construction for urban stormwater management. Front. Environ. Sci. Eng. 2017, 11, 1-2.

[60] Gong, Y.W.; Liang, X.Y.; Li, X.N.; Song, R.N. Influence of rainfall characteristics on total suspended solids in urban runoff: A case study in Beijing, China. Water 2016, 8, 278.

[61] Yao, L.; Chen, L.; Wei, W.; Sun, R. Potential reduction in urban runoff by green spaces in Beijing: A scenario analysis. Urban For. Urban Greening 2015, 14, 300-308.

[62] Xu, T.; Jia, H.; Wang, Z.; Mao, X.; Xu, C. SWMM-based methodology for block-scale LIDBMPs planning based on site-scale multi-objective optimization: A case study in Tianjin. Front. Environ. Sci. Eng. 2017, 11, 51-62.

[63] Cipolla, S.S.; Maglionico, M.; Stojkov, I. A long-term hydrological modelling of an extensive green roof by means of SWMM. Ecol. Eng. 2016, 95, 876-887.

[64] Brunetti,G.; Simunek, J.; Piro, P. A comprehensive analysis of the variably saturated hydraulic behavior of a green roof in Mediterranean climate. Vadose Zone J. 2016, 5, 5:1-5:18. 
[65] Mehring, A.S.; Hatt, B.E.; Kraikittikun, D.; Barbara, D.O.; Megan, A.R.; Stanley, B.G.; Jennifer, P.G.; Sunny, C.J.; Richard, F.A.; Lisa, A.L. Soil invertebrates in Australian rain gardens and their potential roles in storage and processing of nitrogen. Ecol. Eng. 2016, 97, $138-143$.

[66] Guo, J.C.Y.; Luu, T.M. Operation of cap orifice in a rain garden. J. Hydrol. Eng. 2015, 20.

[67] Alias, M.N.; Muhammad, M.M.; Yusof, K.W.; Mustafa, M.R.U.; Ghani, A.A. Hydraulic analysis of biochannels for sustainable urban drainage systems. MATEC Web Conf. 2016, 68, 08002:1-08002:7.

[68] Kuller, M.; Bach, P.M.; Ramirez-Lovering, D.; Deletic, A. Framing water sensitive urban design as part of the urban form: A critical review of tools for best planning practice. Environ. Model. Software 2017, 96, 265-282.

[69] Eggimann, S.; Mutzner, L.; Wani, O.; Schneider, M.Y.; Spuhler, D.; Moy de Virty M.; Beutler, P.; Maurer, M. The potential of knowing more- A review of data-driven urban water management. Environ. Sci. Technol. 2017, 51, 2538-2553.

[70] Tedoldi, D.; Chebbo, G.; Pierlot, D.; Kovacs, Y.; Gromaire, M.C. Impact of runoff infiltration on contaminant accumulation and transport in the soil/filter media of Sustainable Urban Drainage Systems: A literature review. Sci. Total Environ. 2016, 569-570, 904-926.

[71] Vogel, J.R.; Moore, T.L.; Coffman, R.R.; Steven, N.R.; Hutchinson, S.; Mcdonough, K.; Mclemore, A.; McMaine, J. Critical review of technical questions facing Low Impact Development and green infrastructure: A perspective from the great plains. Water Environ. Res. Res. Publ. Water Environ. Fed. 2015, 87, 849.

[72] Xia, J.; Zhang, Y.Y.; Xiong, L.H.; Shan, H.E.; Wang, L.F.; Yu, Z.B. Opportunities and challenges of the Sponge City construction related to urban water issues in China. Sci. China: Earth Sci. 2017, 60, 1-7.

[73] Morihama, A.C.; Amaro, C.; Tominaga, E.N.; Yazaki, L.F.; Pereira1, M.C.; Porto, M.F.; Mukai, P.; Lucci, R.M. Integrated solutions for urban runoff pollution control in Brazilian metropolitan regions. Water Sci. Technol. 2012, 66, 704-711.

[74] Freni, G.; Mannina, G. Uncertainty in water quality modelling: The applicability of Variance Decomposition Approach. J. Hydrol. 2010, 394, 324-333.

[75] Daigger, G.T. Wastewater management in the 21st Century. J. Environ. Eng. 2007, 133, $671-680$.

[76] Cettner, A.; Ashley, R.; HedstrãM, A.; Viklander, M. Sustainable development and urban stormwater practice. Urban Water J. 2014, 11, 185-197.

[77] Berndtsson, J.C.; Jinno, K. Sustainability of urban water system: Examples from Fukuoka, Japan. Water Policy 2008, 10, 501-513. 
[78] Fernández, P.; Santana, J.; Sánchez, A.; et al. A GIS Water Management System Using Free and Open Source Software, Proceedings of the International Conference on Ubiquitous Computing and Ambient Intelligence. Springer International Publishing, 2016, 383-394.

[79] Fuchs, L.; Beeneken, T.; Lindenberg, M. Use of geographic information systems for flooding analysis in urban drainage. Comput. Sci. Inf. Syst. 2012, 627-631.

[80] Jasper, M.D.; Caroline, A.R.; Henri, L.F. de Groot; Peter, N. Sustainable water management policy: Lessons from Amsterdam. Eur. Plann. Studies 2003, 11, 263-281.

[81] Zheng, Z.; Gao, J.Q.; Ma, Z.; Wang, Z.F.; Yang, X.Y.; Luo, X.Z.; Jacquet, T.; Fu, G.T. Urban flooding in China: main causes and policy recommendations. Hydrol. Process. 2016, 30, $1149-1152$.

[82] Candaele, R.M. California zero trash policy and its impacts on urban drainage, Proceedings of the World Environmental and Water Resources Congress. Wuhan, China, January 2017; pp. 403-415.

[83] Mees, H. Governance of adaptation legitimate adaptive flood risk governance beyond the dikes: The cases of Hamburg. Reg. Environ. Change 2014, 14, 671-682.

[84] Yoshiaki, K.; John, W.P. References. In Flood risk management in the People's Republic of China: Learning to live with flood risk. Adb Reports, Asian Development Bank, Philippines and China, 2012, 1-4.

[85] Jach, T.; Magiera, E.; Froelich, W. Application of HADOOP to store and process big data gathered from an urban water distribution system. Procedia Eng. 2015, 119, 1375-1380.

[86] Athanasiou, S.; Staake, T.; Stiefmeier, T.; Sartorius, C.; Tompkins, J.; Lytras, E. DAIAD: Open Water Monitoring. Procedia Eng. 2014, 89, 1044-1049.

[87] Thompson, K.; Kadiyala, R. Making water systems smarter using M2M technology. Procedia Eng. 2014, 89, 437-443. 